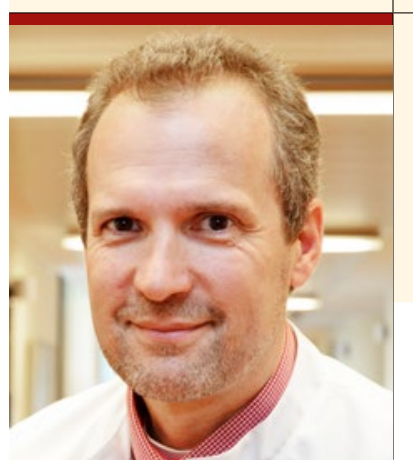

"Die Medizin der Zukunft wird noch mehr eine Medizin des älteren Menschen sein."

\title{
Mit dem Geriatrie-Report fit für die Zukunft
}

E $s$ ist Ihnen sicherlich schon mit der letzten Ausgabe aufgefallen, dass sich der GeriatrieReport etwas verändert hat. Nicht nur die äuBere Aufmachung zeigt sich anders, in erster Linie ist uns die inhaltliche Neuausrichtung wichtig. Wir wollen auf aktuelle Entwicklungen in der Geriatrie eingehen, sektorenübergreifende Themen interdisziplinär diskutieren und neue Akzente in der Fortbildung setzten.

Herr Dr. Joachim Zeeh stellt eindrücklich die Initiative "Choosing Wisely" vor und beschreibt anhand von zwei Fällen, wie wir in der Geriatrie klug entscheiden (S. 7). Auch Dr. Edith A. Boedefeld und Prof. Lothar Weißbach greifen die Thematik der Besonderheiten in der Therapie älterer Patienten in ihrem CME-Beitrag zum Thema Prostatakarzinom auf (S. 40). Prof. Herbert Löllgen und Prof. Alexander Schuh beschäftigen sich intensiv mit dem Thema Bewegung (S. 18) und Bewegungsapparat (S. 36). Auch eine interessante und nicht ganz alltägliche Kasuistik zum Thema Skorbut von Herrn Dr. Andreas Leischker darf nicht fehlen (S. 12).

Wir berichten weiterhin vom Bayerischen Internisten Kongress 2017, in dem es u. a. um die Gefährlichkeit der Pneumonie beim geriatrischen Patienten ging, ein Thema, welches uns immer wieder beschäftigt und eine hohe Relevanz in Klinik und Praxis hat.

Das Ganze wird von verschiedenen Kongressberichten, Interviews und
Literaturbesprechungen abgerundet. Geriatrie wollen wir Ihnen so näherbringen und Sie in Ihrem klinischen und praktischen Alltag unterstützen, indem wir die wichtigen diagnostischen und therapeutischen Neuerungen für Sie fokussiert aufbereiten und gemeinsam im Interesse unserer Patienten mit Ihnen besprechen.

Aber wie wir auch diskutieren oder verhandeln werden, eines steht unverrückbar fest: Die Medizin der Zukunft wird noch mehr eine Medizin des älteren Menschen sein.

So wünsche ich Ihnen viel Spaß bei der interessanten Lektüre. Ich freue mich auf rege Diskussionen und reichlich Vorschläge für die zukünftige Gestaltung des Geriatrie-Reports.

Herzlichst, Ihr

Hans Jürgen Heppner

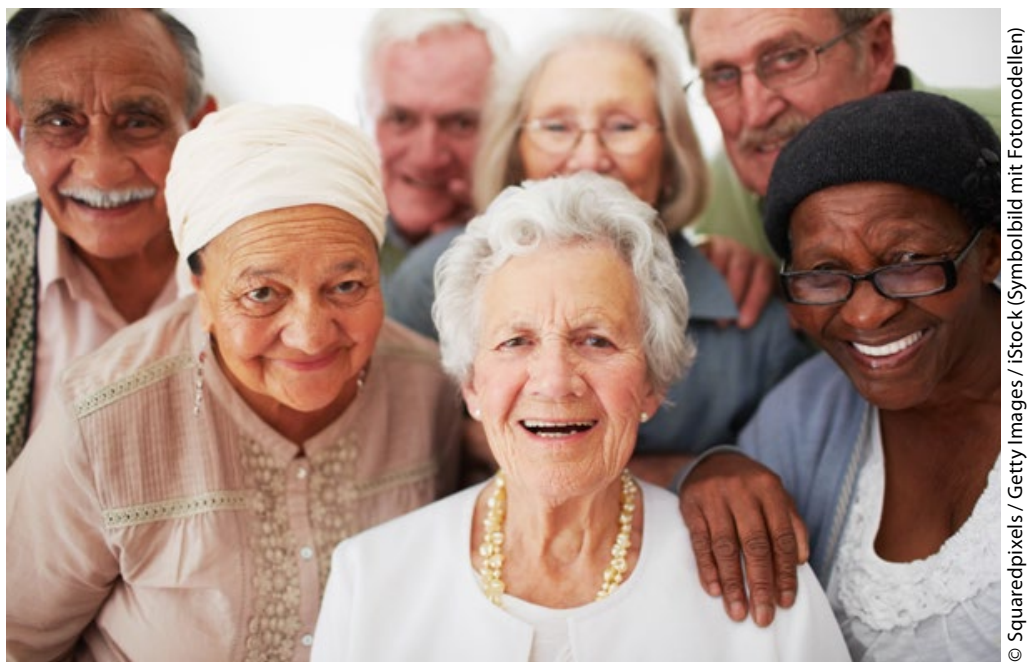

Die Bevölkerung wird immer älter, die Geriatrie umso wichtiger. 